\title{
Erratum to: Why school based assessment is not a universal feature of high stakes assessment systems?
}

\author{
Iasonas Lamprianou • Thomas Christie
}

\section{Erratum to: Educ Asse Eval Acc (2009) 21:329-345 \\ DOI 10.1007/s11092-009-9083-1}

The original version of this article unfortunately contained some mistakes on the caption of figure 1 and on Table notes of Tables 1 and 2. Table 2 has some additional data on the first column. The corrected caption, Table notes and Table 2 are shown below

Figure 1 caption should read as:

Fig. 1 Model of the variance in a pupils (p) within schools (s) by subjects (c) by internal/external assessment (f) analysis of variance with $p, s$ and $c$ random and $f$ fixed.

Table 1 footnotes should read as follows

${ }^{a}$ Mean is the average of the \% of raw score variance estimates attributed to each source (facets and interactions) over all 18 subjects

The online version of the original article can be found at http://dx.doi.org/10.1007/s11092-009-9083-1.

I. Lamprianou

School of Education, University of Manchester, Manchester, UK

I. Lamprianou $(\bowtie)$

Department of Education Sciences, European University-Cyprus, P.O. Box 22006, Nicosia 1516, Cyprus

e-mail: iasonas.lamprianou@man.ac.uk

T. Christie

Aga Khan University Examination Board, Karachi, Sindh, Pakistan

e-mail: thomas.christie@aku.edu 
${ }^{\mathrm{b}}$ S.D. is the standard deviation of the $\%$ of raw score variance estimates attributed to each source (facets and interactions) over all 18 subjects

${ }^{c}$ Mann-Whitney $U$ test also gave statistically significant results at the 0.05 level The $\mathrm{t}$ and $\mathrm{p}$ values on the table refer to the difference between the means (averaged variance estimates) of the 13 subjects where SBA is not followed by an external examination and the 18 subjects where an external exam follows. Values of $\mathrm{p}$ smaller than 0.05 indicate statistical significance

The corrected Table 2 appears below

Table 2 Averaged variance estimates over 18 subjects where SBA is followed by an external examination before and after taking out the regression of the final examination

\begin{tabular}{lllllll}
\hline Source & \multicolumn{2}{c}{ Raw score variance estimates } & & \multicolumn{2}{c}{ Residual variance estimates } & \multirow{2}{*}{$\begin{array}{l}\text { \% variance explained } \\
\text { by external exam }\end{array}$} \\
\cline { 2 - 3 } & Mean $^{\mathrm{a}}$ & S.D. $^{\mathrm{b}}$ & & Mean $^{\mathrm{a}}$ & S.D. & \\
\hline $\mathrm{o}$ & 0.019 & 0.029 & & 0.033 & 0.027 & 0 \\
$\mathrm{~s}$ & 0.518 & 0.304 & & 0.223 & 0.157 & 57 \\
$\mathrm{os}$ & 0.146 & 0.100 & & 0.001 & 0.003 & 99 \\
$\mathrm{p}(\mathrm{s})$ & 6.130 & 1.707 & & 3.111 & 1.399 & 49 \\
op(s),e & 0.787 & 0.235 & & 0.011 & 0.014 & 99 \\
Total (raw) & 7.601 & 1.702 & & 3.379 & 1.449 & 55 \\
\hline
\end{tabular}

a Mean is the average of the raw score variance estimates attributed to each source (facets and interactions) over all 18 subjects

b S.D. is the standard deviation of the raw score variance estimates attributed to each source (facets and interactions) over all 18 subjects 